\title{
Sistemas de preparo do solo e rotação de culturas na produtividade de milho, soja e trigo
}

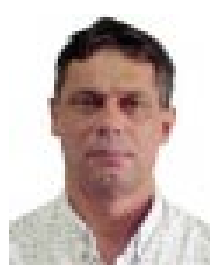

Pedro M. da Silveira ${ }^{1} \&$ Luís F. Stone ${ }^{2}$

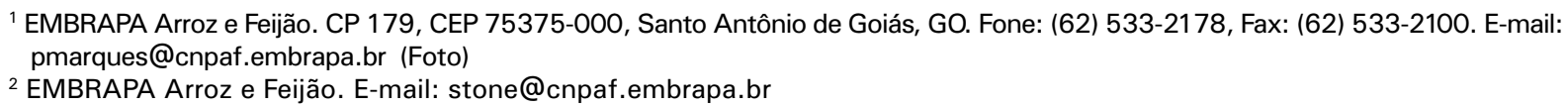

Protocolo $66-7 / 5 / 2002$ - Aprovado em 16/4/2003

\begin{abstract}
Resumo: Com este trabalho, objetivou-se determinar quanto os sistemas de preparo do solo e as rotações de culturas afetam a produtividade de grãos do milho, da soja e do trigo. $O$ experimento foi conduzido em um Latossolo Vermelho distrófico, em área irrigada por pivô central, na EMBRAPA Arroz e Feijão, em Santo Antônio de Goiás, GO, por seis anos, setembro de 1992 a setembro de 1998, durante os quais foram feitos 12 cultivos e comparados três sistemas de preparo do solo: a) aração com arado de aiveca, realizada em novembro-dezembro e em maio-junho; b) aração com grade aradora, em ambos os períodos, e c) plantio direto e quatro rotações de cultura: 1) milho-feijão; 2) soja-trigo; 3) soja-trigo-soja-feijão-arroz-feijão e 4) milho-feijão-milho-feijão-arroz-feijão. As culturas de arroz, soja e milho, foram semeadas em novembro-dezembro e as de feijão e trigo, em maio-junho. Para efeito do estudo, consideraramse somente as culturas do milho, da soja e do trigo. O sistema de preparo do solo não afetou a produtividade de soja mas, sim, a de milho e de trigo, tendo o preparo com arado propiciado maiores produtividades em comparação com o plantio direto. As diferenças entre o plantio direto e os demais sistemas de preparo do solo, com relação à produtividade acumulada relativa de milho, diminuíram com o tempo de cultivo. Não houve efeito da rotação de culturas sobre a produtividade das culturas estudadas.
\end{abstract}

Palavras-chave: arado, grade aradora, plantio direto, sistema agrícola

\section{Tillage systems and crop rotation on yield of corn, soybean and wheat}

\begin{abstract}
The objective of this study was to determine how much soil tillage and crop rotation affected grain yield of corn, soybean and wheat. The study was carried out at EMBRAPA (Rice and Beans), in Santo Antônio de Goiás, GO, Brazil, in a Red Latosol (Oxisol), under center pivot irrigation system, for six consecutive years. During the experimentation, 12 crops were cultivated. The tillage treatments were a) moldboard plough, b) harrow disc and c) no-tillage. The crop rotations were 1) corn-bean, 2) soybean-wheat, 3) soybean-wheat-soybean-bean-upland rice-bean and 4) corn-bean-corn bean-upland rice-bean. Rice, soybean and corn were sown in November/December and bean and wheat in May/June. For this study, only corn, soybean and wheat were considered. Soil tillage affected corn and wheat yields but did not affect soybean yield. Corn and wheat yields under mouldboard plough were higher than under no-tillage. The differences among no-tillage and the other tillage systems in relation to relative accumulative corn yield decreased as the cultivation period increased. Crop rotations did not affect the crop yields.
\end{abstract}

Key words: moldboard plough, harrow disc, no-tillage, agricultural system

\section{INTRODUÇÃO}

Os Latossolos argilosos do cerrado brasileiro, suscetíveis à compactação, têm sido utilizados com sistemas de preparo que revolvem o solo. Este revolvimento, associado a chuvas intensas, de alta erosividade, e a temperaturas elevadas, degrada rapidamente o solo, comprometendo a sustentabilidade da atividade agrícola.

O sistema de preparo do solo com grade aradora tem sido o mais usado nessa região. Normalmente, a grade trabalha o solo a pouca profundidade e apresenta alto rendimento de campo, porém o uso contínuo desse implemento pode levar à formação de camadas compactadas, chamadas "pé-de-grade" (Silva, 1992). O arado de aiveca é pouco usado porque requer maior tempo e energia para a sua operação que os demais implementos, embora se tenha obtido maior produtividade de milho, de soja e de trigo (Balbino \& Oliveira, 1992; Kochhann \& Denardim, 1997; Kluthcouski et al., 2000) quando comparado com o plantio direto ou com o preparo com grade aradora. Isto ocorreu devido 
ao pior desenvolvimento do sistema radicular nesses sistemas de preparo, por causa da compactação do solo na camada superficial ou subsuperficial, respectivamente.

O plantio direto pode ser uma alternativa ao sistema convencional de preparo do solo e contribuir para a sustentabilidade de sistemas agrícolas intensivos, por manter o solo coberto por restos culturais ou por plantas vivas o ano inteiro, minimizando os efeitos da erosão e, ainda, manter o conteúdo de matéria orgânica (Albuquerque et al., 1995). Entretanto, no sistema plantio direto, em geral, os solos apresentam, na camada superficial, após três a quatro anos, maiores valores de densidade e microporosidade, e menores valores de macroporosidade e porosidade total, quando comparado com o preparo convencional, decorrente, sobretudo, do arranjamento natural do solo quando não é mobilizado, e da pressão provocada pelo trânsito de máquinas e implementos agrícolas, em particular quando realizado em solos argilosos e com teores elevados de umidade (Vieira \& Muzilli, 1984; Corrêa, 1985; Castro, 1989). O aumento do conteúdo de matéria orgânica com o tempo nesse sistema, porém, pode reduzir a densidade do solo, como observado por Reeves (1995). Em condições de clima temperado, Voorhees \& Lindstrom (1984) verificaram que, após três a quatro anos, o solo sob plantio direto apresentou maior porosidade que o preparado com arado de aiveca. Assim, em condições de plantio direto estabilizado, maiores produtividades de milho, soja e trigo, foram obtidas em relação a preparos que mobilizavam mais o solo (Hernani, 1997; Hernani et al., 1997; Santos et al., 2000).

Cultivos contínuos das mesmas espécies, como acontece em áreas irrigadas por pivô central, podem ocasionar, com o passar dos anos, queda na produtividade, cujo fato ocorre porque se alteram as características do solo e as condições do ambiente se tornam propícias à multiplicação de pragas e doenças. A maneira para se solucionar ou atenuar esses problemas é a prática de rotação de culturas, a qual, pela inclusão de espécies com sistema radicular vigoroso e pelos aportes diferenciados de matéria seca, pode alterar as propriedades físicas e químicas do solo. A intensidade da alteração depende do período de cultivo, do número de cultivos por ano e das espécies cultivadas.

O objetivo deste trabalho foi avaliar os efeitos de sistemas de preparo do solo e de rotações de culturas sobre a produtividade do milho, da soja e do trigo.

\section{MATERIAL E MÉTODOS}

O trabalho foi conduzido em um Latossolo Vermelho distrófico, em área irrigada por pivô central, na Fazenda Capivara, da EMBRAPA Arroz e Feijão, localizada no município de Santo Antônio de Goiás, GO, por seis anos, setembro de 1992 a setembro de 1998, durante os quais foram feitos 12 cultivos.

Compararam-se três sistemas de preparo do solo: a) aração com arado de aiveca, realizada em novembro-dezembro e em maio-junho (arado); b) aração com grade aradora, em ambos os períodos (grade); e c) plantio direto, e quatro rotações de cultura: a) milho-feijão (M-F); b) soja-trigo (S-T); c) soja-trigo-soja- feijão-arroz-feijão (S-T-S-F-A-F); e d) milho-feijão-milho-feijãoarroz-feijão (M-F-M-F-A-F). No preparo do solo e de acordo com o tratamento, foram utilizados arado de três aivecas comuns, operando na profundidade de aproximadamente $30 \mathrm{~cm}$, e grade aradora de 20 discos de $66 \mathrm{~cm}$ de diâmetro, operando de 10 a $15 \mathrm{~cm}$. As culturas do arroz, da soja e do milho foram semeadas em novembro-dezembro e as do feijão e do trigo, em maio-junho. Para efeito deste estudo, foram consideradas apenas as culturas do milho, da soja e do trigo.

Em média, as doses de adubo aplicadas por safra foram de $72 \mathrm{~kg} \mathrm{ha}^{-1}$ de $\mathrm{N}, 94 \mathrm{~kg} \mathrm{ha}^{-1}$ de $\mathrm{P}_{2} \mathrm{O}_{5}$ e $53 \mathrm{~kg} \mathrm{ha}^{-1}$ de $\mathrm{K}_{2} \mathrm{O}$, para o milho, $61 \mathrm{~kg} \mathrm{ha}^{-1} \mathrm{de} \mathrm{N}, 110 \mathrm{~kg} \mathrm{ha}^{-1} \mathrm{de}_{2} \mathrm{O}_{5}$ e $56 \mathrm{~kg} \mathrm{ha}^{-1} \mathrm{de}_{2} \mathrm{O}$, para o trigo, e $73 \mathrm{~kg} \mathrm{ha}^{-1} \mathrm{de}_{2} \mathrm{O}_{5}$ e $67 \mathrm{~kg} \mathrm{ha}^{-1}$ de $\mathrm{K}_{2} \mathrm{O}$, para a soja. Os híbridos de milho variaram a cada ano agrícola, sendo utilizados, na ordem, Agroceres IEX-9252, Cargill 701, Agroceres 510, Cargill 915, Cargill 333 e Cargill 435, no espaçamento de $0,90 \mathrm{~m}$ entre linhas. As cultivares de soja utilizadas foram Doko RS (1, 2, 4, 5 e $6^{\circ}$ anos) e Emgopa 305 ( $3^{\circ}$ ano) semeadas no espaçamento de $0,45 \mathrm{~m}$ entre linhas, com cerca de 30 sementes por metro, tratadas com inoculante específico. Utilizaram-se as cultivares de trigo BR-33 Guará (1, 2,3 e $4^{\circ}$ anos) e a BR-42 Formosa ( 5 e $6^{\circ}$ anos) no espaçamento de $0,25 \mathrm{~m}$ entre linhas.

$\mathrm{Na}$ cultura do trigo, foram feitas irrigações para elevar o conteúdo de água do solo à capacidade de campo $(-10 \mathrm{kPa})$ sempre que a média da leitura de três tensiômetros instalados a $15 \mathrm{~cm}$ de profundidade se situava na faixa de -30 a $-40 \mathrm{kPa}$.

As produtividades das culturas foram determinadas em áreas de 7,2 $\mathrm{m}^{2}$. Para a análise de variância dos dados, considerou-se o delineamento inteiramente casualizado no esquema de parcelas subdivididas, com os sistemas de preparo do solo nas parcelas e as rotações de culturas nas subparcelas. No caso dos sistemas de preparo do solo, o número de repetições variou com os anos, sendo igual a 8 ou 16, dependendo do número de rotações em que a cultura participava no ano (uma ou duas). No caso dos sistemas de rotação, o número de repetições foi igual a 24 (oito repetições x três sistemas de preparo). Fez-se a análise de variância conjunta dos anos, cujas médias foram comparadas pelo teste de Tukey a $5 \%$.

Considerando-se que o preparo com grade tem sido o mais usado na região, determinou-se a produtividade acumulada nos diferentes tratamentos, em \% da obtida nesse preparo, relacionando-a com o tempo de cultivo, ajustando-se modelos matemáticos aos dados.

\section{RESULTADOS E DISCUSSÃO}

Não houve interação significativa entre sistemas de preparo do solo e rotações de culturas sendo, portanto, discutidos os efeitos isolados dessas duas variáveis sobre a produtividade das culturas consideradas.

A produtividade do milho sob preparo do solo com arado de aiveca foi, na média dos seis anos, 9 e $7 \%$ superior às obtidas no preparo com grade e no plantio direto, respectivamente (Tabela 1), sem dúvida pela não ocorrência dos aspectos negativos da compactação subsuperficial (pé-de-grade) que se verifica no preparo com grade aradora e da compactação superficial que ocorre no plantio direto. A produtividade média 
Tabela 1. Produtividades do milho, da soja e do trigo, relativas aos sistemas de preparo do solo e ao período 1992-1998

\begin{tabular}{|c|c|c|c|c|c|c|c|}
\hline \multirow{2}{*}{$\begin{array}{l}\text { Sistema de } \\
\text { Preparo }\end{array}$} & \multicolumn{7}{|c|}{ Produtividade $\left(\mathrm{kg} \mathrm{ha}^{-1}\right)$} \\
\hline & $1992 / 93$ & $1993 / 94$ & $1994 / 95$ & $1995 / 96$ & $1996 / 97$ & $1997 / 98$ & Média $^{1}$ \\
\hline \multicolumn{8}{|c|}{ Milho } \\
\hline Arado & 7579 & 7325 & 5705 & 8785 & 8814 & 6338 & $7707 \mathrm{a}(109)$ \\
\hline Grade & 7134 & 6594 & 5151 & 8182 & 8115 & 6118 & $7072 b(100)$ \\
\hline Plantio direto & 6672 & 6519 & 5225 & 8543 & 9080 & 5920 & $7179 b(102)$ \\
\hline \multicolumn{8}{|c|}{ Soja } \\
\hline Arado & 3106 & 2636 & 3004 & 3549 & 2545 & 2379 & $2830(99)$ \\
\hline Grade & 3100 & 2760 & 2366 & 3506 & 2745 & 2675 & $2861(100)$ \\
\hline Plantio direto & 3035 & 2614 & 2277 & 3294 & 3126 & 1953 & $2756(96)$ \\
\hline \multicolumn{8}{|c|}{ Trigo } \\
\hline Arado & 3382 & 3803 & 3918 & 3021 & 3687 & 2453 & 3381a (101) \\
\hline Grade & 2967 & 3570 & 4188 & 3463 & 3969 & 2544 & $3362 \mathrm{a}(100)$ \\
\hline Plantio direto & 2939 & 2855 & 3030 & 2445 & 3465 & 1790 & $2783 b(83)$ \\
\hline
\end{tabular}

${ }^{1}$ Valores ponderados pelo número de rotações em que a cultura participava a cada ano; dentro de cultura, médias da análise conjunta seguidas pela mesma letra não diferem pelo teste de Tukey a $5 \%$ de probabilidade; valores entre parênteses são relativos à grade

obtida sob plantio direto não diferiu significativamente da obtida no preparo com grade. Esses resultados concordam com os obtidos por Kluthcouski et al. (2000) em solo de cerrado. Balbino \& Oliveira (1992) no Paraná, também verificaram, em Latossolo Roxo, que o preparo do solo com arado de aiveca proporcionou produtividades de milho maiores ou semelhantes às obtidas com o preparo com grade ou no plantio direto. Benatti Junior et al. (1984) no estado de São Paulo, em Latossolo Roxo, e Zaffaroni et al. (1991) na Paraíba, em Latossolo VermelhoAmarelo, não encontraram, entretanto, diferenças significativas entre o preparo do solo com arado de discos e o plantio direto, com relação à produtividade do milho. Salienta-se que neste experimento, no plantio direto cada cultura era semeada na resteva da anterior e as condições climáticas da região, com verão quente e úmido e inverno com temperaturas médias acima de $20^{\circ} \mathrm{C}$, aliadas à prática da irrigação, favorecem a rápida mineralização do material orgânico. Não havia cultura específica de cobertura que poderia contribuir para aumentar mais rapidamente o conteúdo de matéria orgânica e reduzir a densidade do solo com o tempo, como observado por Reeves (1995). Em condições de clima temperado, Voorhees \& Lindstrom (1984) verificaram que, após três a quatro anos, o solo sob plantio direto apresentou maior porosidade que o preparado com arado de aiveca. O que se espera do plantio direto, quando o solo permanece coberto por material vegetal todo o tempo, é que haja alta concentração de material orgânico na camada superficial, promovendo intensa atividade biológica, resultando em produtos que desempenham função na formação e estabilização (agentes cimentantes) dos agregados. Os efeitos benéficos sobre essa agregação são o resultado da atividade conjunta dos microrganismos, da fauna e da vegetação, resultando em maior porosidade e menor densidade do solo.

As produtividades acumuladas de milho, referentes ao preparo com arado, ajustaram-se a um modelo quadrático (Figura 1), situando-se sempre acima das obtidas com o preparo com grade. O plantio direto, por sua vez, propiciou produtividades sempre crescentes ao longo do tempo, em relação ao preparo com grade, ultrapassando as produtividades obtidas com esse preparo, após quatro anos de cultivo devido, provavelmente, à melhoria com o tempo nas condições físicas do solo sob plantio direto. Henklain et al. (1996) verificaram que o desenvolvimento e a distribuição do sistema radicular
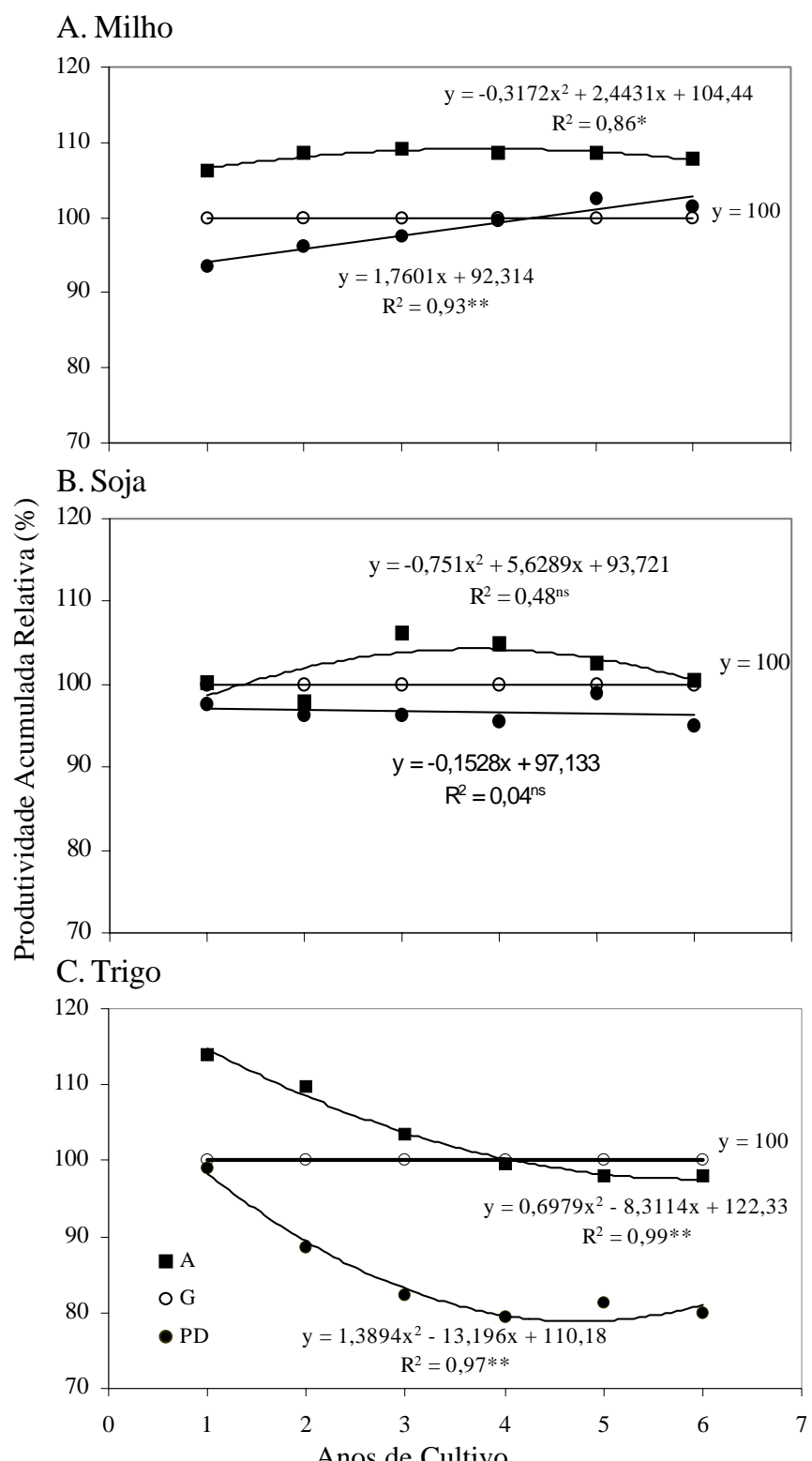

Figura 1. Produtividades acumuladas de milho (A), soja (B) e trigo (C), em diferentes sistemas de preparo do solo: A - arado, $\mathrm{G}$ - grade e PD - plantio direto, em relação ao preparo com grade, em função do tempo de cultivo 
foram melhores sob plantio direto em comparação com o preparo convencional do solo, em virtude da qualidade dos poros que, embora menores, apresentaram-se contínuos ao longo do perfil, aos canais e galerias formados pela atividade biológica e decomposição das raízes das culturas anteriores e às fendas provocadas pelos gradientes de umidade.

Os sistemas de preparo do solo não tiveram efeito significativo sobre a produtividade da soja, na média dos seis anos (Tabela 1), concordando com os resultados obtidos por Kluthcouski et al. (2000). Balbino \& Oliveira (1992) por sua vez, verificaram que o plantio direto e o preparo com arado proporcionaram produtividades de soja maiores ou semelhantes às obtidas com o preparo com grade.

As produtividades acumuladas relativas a soja, no preparo com arado e no plantio direto, apresentaram pequena amplitude de variação e não se ajustaram a um modelo matemático (Figura 1).

Constatou-se efeito significativo dos tratamentos de preparo do solo sobre a produtividade de trigo, sendo as menores produtividades obtidas no plantio direto (Tabela 1), cujos resultados contrariam os obtidos por Santos et al. (2000) no Rio Grande do Sul, e os de Hernani et al. (1997) na região de Dourados, MS, que verificaram que a produtividade de trigo sob plantio direto foi superior às obtidas com preparo do solo com arado de disco, de aiveca, ou com grade aradora. Balbino \& Oliveira (1992) verificaram que o plantio direto e o preparo com arado proporcionaram produtividades de trigo maiores ou semelhantes às obtidas com o preparo com grade. Stone \& Silveira (2001) na mesma área experimental deste trabalho, constataram que as rotações que incluíam soja e trigo propiciaram, na camada de $0-10 \mathrm{~cm}$ de profundidade, maior valor de densidade do solo. Entre as culturas estudadas, a do trigo é a semeada no menor espaçamento, o que condiciona a passagem das rodas compactadoras em maior área de solo. Além disso, segundo Fahad et al. (1982), a soja tem efeito negativo na agregação do solo.

Como discutido antes, a rápida mineralização do material orgânico que ocorre na região tropical faz com que os possíveis benefícios do plantio direto sobre as condições físicas do solo demorem mais a ocorrer; entretanto, observa-se, na Figura 1, que, apesar do plantio direto propiciar produtividades relativas de trigo decrescentes ao longo do tempo, esta tendência começou a reverter após cinco anos de cultivo. No preparo com arado, as produtividades relativas também decresceram segundo um modelo quadrático, atingindo valores semelhantes aos obtidos no preparo com grade, após quatro anos.

Com relação às rotações de cultura, observou-se que as produtividades obtidas no cultivo anual de milho, soja ou trigo, não diferiram significativamente daquelas obtidas quando se utilizaram intervalos maiores de cultivo (Tabela 2), resultados esses que concordam com os obtidos no Paraná por Santos et al. (1994) para a soja, e por Santos et al. (1995) para o trigo. Mascarenhas et al. (1993) também observaram, no estado de São Paulo, que a produtividade da soja em monocultura ou em rotação não diferiu significativamente. Esses resultados, contudo, são discordantes dos obtidos na região dos cerrados por Corrêa et al. (1986) para milho e soja, e no estado de São Paulo, por Mascarenhas et al. (1993) para milho, que observaram aumentos da produtividade em cultivos bienais ou trienais, em relação ao cultivo anual. Santos et al. (1998) por outro lado, também verificaram, no Rio Grande do Sul, que o trigo semeado com apenas um inverno de rotação de culturas ou após seu cultivo por dois invernos seguidos, deixando-se dois invernos de rotação, produziu mais que o trigo em monocultura contínua. Provavelmente, essas diferenças são devidas às culturas participantes das rotações e às condições climáticas, entre outros fatores.

Tabela 2. Produtividades do milho, da soja e do trigo, relativas às rotações de cultura e ao período 1992-1997

\begin{tabular}{lccccc}
\hline \multicolumn{1}{c}{$\begin{array}{c}\text { Rotação de } \\
\text { Cultura }\end{array}$} & \multicolumn{5}{c}{ Produtividade $\left(\mathrm{kg} \mathrm{ha}^{-1}\right)$} \\
\cline { 2 - 6 } & $1992 / 93$ & $1993 / 94$ & $1995 / 96$ & $1996 / 97$ & Média $^{2}$ \\
M-F & 6669 & 6711 & 8600 & 8492 & $7618(100)$ \\
M-F-M-F-A-F & 7812 & 6827 & 8546 & 8570 & $7939(104)$ \\
\hline & & \multicolumn{5}{c}{ Soja } \\
S-T & 3254 & 2770 & 3486 & 2855 & $3091(100)$ \\
S-T-S-F-A-F & 2918 & 2603 & 3302 & 2723 & $2886(93)$ \\
\hline & 3171 & - & 2824 & - & $2998(100)$ \\
S-T & 3183 & - & 3352 & - & $3268(109)$ \\
S-T-S-F-A-F & &
\end{tabular}

${ }^{1} \mathrm{M}$ - milho, F - feijão, A - arroz, S - soja, T - trigo

${ }^{2}$ Valores entre parênteses são relativos ao cultivo anual

\section{CONCLUSÕES}

1. O sistema de preparo do solo não afetou a produtividade de soja mas, sim, a de milho e de trigo, tendo o preparo com arado de aiveca propiciado maiores produtividades em comparação com o plantio direto.

2. As diferenças entre o plantio direto e os demais sistemas de preparo do solo, quanto à produtividade acumulada relativa de milho, diminuíram com o tempo de cultivo.

3. Não houve efeito da rotação sobre a produtividade das culturas estudadas.

\section{LITERATURA CITADA}

Albuquerque, J.A.; Reinert, D.J.; Fiorin, J.E.; Ruedell, J.; Petrere, C.; Fontinelli, F. Rotação de culturas e sistemas de manejo do solo: efeito sobre a forma da estrutura do solo ao final de sete anos. Revista Brasileira de Ciência do Solo, Viçosa, v.19, n.1, p.115-119, 1995.

Balbino, L.C.; Oliveira, E.F. de. Efeito do sistema de preparo do solo no rendimento de grãos de trigo, soja e milho. In: Congresso Brasileiro de Engenharia Agrícola, 20, 1991, Londrina. Anais... Londrina: SBEA, 1992. v.2, p.1354-1360.

Benatti Junior, R.; Moreira, C.A.; Franca, G.V. Avaliação dos efeitos de sistemas de cultivo na produção de milho e nas propriedades edáficas em Latossolo Roxo, no Estado de São Paulo. Revista Brasileira de Ciência do Solo, Campinas, v.8, n.1, p.139-144, 1984.

Castro, O.M. de. Compactação do solo em plantio direto. In: Fancelli, A.L. (coord.). Plantio direto no Estado de São Paulo. Piracicaba: FEALQ/ESALQ, 1989. p.129-139.

Corrêa, J.C. Efeito de métodos de cultivo em algumas propriedades físicas de um Latossolo Amarelo muito argiloso do Estado do Amazonas. Pesquisa Agropecuária Brasileira, Brasília, v.20, n.11, p.1317-1322, 1985. 
Corrêa, L.A.; Silva, A.F.; Cruz, J.C.; Silva, B.G.; Coelho, A.M. Sistema de produção de milho em monocultivo. In: EMBRAPA. Centro Nacional de Pesquisa de Milho e Sorgo (Sete Lagoas, MG). Relatório técnico anual do Centro Nacional de Pesquisa de Milho e Sorgo: 1980-1984. Sete Lagoas: Embrapa-CNPMS, 1986. p.99-101.

Fahad, A.A.; Mielke, L.N.; Flowerday, A.D.; Swartzendruber, D. Soil physical properties as affected by soybean and other cropping sequences. Soil Science Society of America Journal, Madison, v.46, n.2, p.377-381, 1982.

Henklain, J.C.; Guimarães, M.F.; Vieira, M.J.; Medina, C.C. Efeito do preparo do solo no desenvolvimento radicular. In: Congresso Brasileiro de Plantio Direto para uma Agricultura Sustentável, 1, 1996, Ponta Grossa. Resumos expandidos... Ponta Grossa: IAPAR, 1996. p.103-105.

Hernani, L.C. Manejo e conservação de recursos naturais da região Oeste do Brasil. In: EMBRAPA. Centro de Pesquisa Agropecuária do Oeste (Dourados, MS). Milho: informações técnicas. Dourados: Embrapa-CPAO, 1997. p.39-67.

Hernani, L.C.; Salton, J.C.; Fabrício, A.C.; Dedecek, R.; Alves Júnior, M. Perdas por erosão e rendimentos de soja e de trigo em diferentes sistemas de preparo de um Latossolo Roxo de Dourados (MS). Revista Brasileira de Ciência do Solo, Viçosa, v.21, n.4, p.667-676, 1997.

Kluthcouski, J.; Fancelli, A.L.; Dourado-Neto, D.; Ribeiro, C.M.; Ferraro, L.A. Manejo do solo e o rendimento da soja, milho, feijão e arroz em plantio direto. Scientia Agrícola, Piracicaba, v.57, n.1, p.97-104, 2000.

Kochhann, R.A.; Denardin, J.E. Comportamento das culturas de trigo, soja e milho à adubação fosfatada no sistema de plantio direto e preparo convencional. In: Seminário Internacional do Sistema Plantio Direto, 2, 1997, Passo Fundo. Anais... Passo Fundo: Embrapa-CNPT, 1997. p.243-246.

Mascarenhas, H.A.A.; Nagai, V.; Gallo, P.B.; Pereira, J.C.V.N.A.; Tanaka, R.T. Sistemas de rotação de culturas de milho, algodão e soja e seu efeito sobre a produtividade. Bragantia, Campinas, v.52, n.1, p.53-61, 1993.

Reeves, D.W. Soil management under no-tillage: Soil physical aspects. In: Seminário Internacional do Sistema Plantio Direto, 1, 1995, Passo Fundo. Resumos... Passo Fundo: Embrapa-CNPT, 1995. p.127-130.
Santos, H.P. dos; Fancelli, A.L.; Reis, E.M.; Lhamby, J.C.B. Efeito da rotação de culturas no rendimento de grãos e na severidade de doença do sistema radicular de trigo em sistema plantio direto. Pesquisa Agropecuária Brasileira, Brasília, v.30, n.7, p.923-929, 1995.

Santos, H.P. dos; Lhamby, J.C.B.; Prestes, A.M.; Lima, M.R. de. Efeito de manejo de solo e de rotação de culturas de inverno no rendimento e doenças de trigo. Pesquisa Agropecuária Brasileira, Brasília, v.35, n.12, p.2355-2361, 2000.

Santos, H.P. dos; Lhamby, J.C.B.; Prestes, A.M.; Reis, E.M. Características agronômicas e controle de doenças radiculares de trigo, em rotação com outras culturas de inverno. Pesquisa Agropecuária Brasileira, Brasília, v.33, n.3, p.277-288, 1998.

Santos, H.P. dos; Pereira, L.R.; Reis, E.M. Rotação de culturas em Guarapuava. XIII. Efeitos de sistemas de sucessão de culturas sobre o rendimento de grãos e sobre outras características agronômicas de soja, em plantio direto. Pesquisa Agropecuária Brasileira, Brasília, v.29, n.6, p.907-916, 1994.

Silva, J.G. Ordens de gradagem e sistemas de aração do solo: desempenho operacional, alterações na camada mobilizada e respostas do feijoeiro (Phaseolus vulgaris L.). Botucatu: UNESP, 1992. 180p. Tese Doutorado

Stone, L.F.; Silveira, P.M. da. Efeitos do sistema de preparo e da rotação de culturas na porosidade e densidade do solo. Revista Brasileira de Ciência do Solo, Viçosa, v.25, n.2, p.395401, 2001.

Vieira, M.J.; Muzilli, O. Características físicas de um Latossolo Vermelho-Escuro sob diferentes sistemas de manejo. Pesquisa Agropecuária Brasileira, Brasília, v.19, n.7, p.873-882, 1984.

Voorhees, W.B.; Lindstrom, M.J. Long-term effects of tillage method on soil tilth independent of wheel traffic compaction. Soil Science Society of America Journal, Madison, v.48, n.1, p.152-156, 1984.

Zaffaroni, E.; Barros, H.H. de A.; Nobrega, J.A.M.; Lacerda, J.T. de; Souza Junior, V.E. de. Efeito de métodos de preparo do solo na produtividade e outras características agronômicas de milho e feijão no Nordeste do Brasil. Revista Brasileira de Ciência do Solo, Campinas, v.15, n.1, p.99-104, 1991. 